\title{
Multicenter implementation of geriatric assessment in Belgian patients with cancer: A survey on treating physicians' general experiences and expectations
}

\section{Cindy Kenis ${ }^{a, l, 1}$, Pieter Heeren ${ }^{b, 1}$, Dominique Bron ${ }^{c}$, Lore Decoster ${ }^{d}$, Ramona Moor ${ }^{e}$, Thierry Pepersack ${ }^{f}$, Christine Langenaeken ${ }^{g}$, Marika Rasschaert ${ }^{h}$, Guy Jerusalem ${ }^{i}$, Ruud Van Rijswijk ${ }^{j}$, Jean-Pierre Lobelle ${ }^{k}$, Johan Flamaing ${ }^{l, m}$, Koen Milisen ${ }^{b, l}$, Hans Wildiers ${ }^{a, n, *}$}

\footnotetext{
${ }^{a}$ Department of General Medical Oncology, University Hospitals Leuven, Leuven, Belgium

${ }^{\mathrm{c}}$ Department of Hematology, ULB Institut Bordet, Brussels, Belgium

eDepartment of Medical Oncology, Cliniques Universitaires Saint-Luc, UCL, Brussels, Belgium,

gepartment of Medical Oncology, Iridium Cancer Network Antwerp, AZ Klina, Brasschaat, Belgium

${ }^{\mathrm{h}}$ Department of Medical Oncology, Iridium Cancer Network Antwerp, St. Augustinus, Wilrijk, Belgium

${ }^{\mathrm{i} D e p a r t m e n t}$ of Medical Oncology, Centre Hospitalier Universitaire Sart Tilman, Liege, Belgium

${ }^{j}$ Department of Medical Oncology, ZNA Stuivenberg, Antwerp, Belgium

${ }^{\mathrm{k}}$ Consultant in Statistics, Beernem, Belgium

${ }^{l}$ Department of Geriatric Medicine, University Hospitals Leuven, Leuven, Belgium

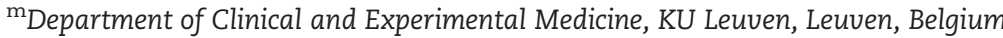

${ }^{\mathrm{n}}$ Department of Oncology, KU Leuven, Leuven, Belgium
}

${ }^{b}$ Department of Public Health and Primary Care, Health Services and Nursing Research, KU Leuven, Leuven, Belgium

${ }^{\mathrm{d}}$ Department of Medical Oncology, Oncologisch Centrum, Universitair Ziekenhuis Brussel, Vrije Universiteit Brussel, Brussels, Belgium

${ }^{f}$ Department of Geriatric Medicine, University Hospital Erasme, Université Libre de Bruxelles (ULB), Brussels, Belgium

\section{A R T I C L E I N F O}

Article history:

Received 7 February 2014

Received in revised

form 11 April 2014

Accepted 10 June 2014

Available online 29 June 2014

Keywords:

Cancer

Geriatric assessment

Older person

\begin{abstract}
A B S T R A C T
Objectives: The aim of this study is to identify treating physicians' general experiences and expectations regarding geriatric assessment (GA) in older patients with cancer.

Materials and Methods: A survey was carried out in 9 Belgian hospitals, which participated in a national GA implementation project focusing on older patients with cancer. A newly developed questionnaire was completed by their treating physicians. Data collection comprised of reviewing hospital data, general respondent data, and treating physicians' general experiences and expectations regarding GA. Descriptive statistics were calculated. Results: Eighty-two physicians from 9 hospitals participated. The GA team composition can vary substantially, with a nurse as core member. Ideally, all older patients with cancer in whom a treatment decision is necessary, should benefit from the GA. Nearly all GA domains are reported as very important. Availability of GA results can be improved. Treating physicians want geriatricians to coordinate geriatric recommendations related to the
\end{abstract}

\footnotetext{
* Corresponding author at: Herestraat 49, 3000 Leuven, Belgium. Tel.: +32 163469 20; fax: +32 16346901 E-mail address: hans.wildiers@uzleuven.be (H. Wildiers).

${ }^{1}$ Equal contribution.
} 
identified GA problems, and expect from trained healthcare workers (THCWs) to collect GA data, to report GA results, and to follow-up the implementation of geriatric recommendations.

Conclusion: This study identifies relevant information for improving the implementation of GA in older patients with cancer in Belgium and reveals priorities for a THCW from the treating physician's point of view. To increase the effectiveness of GA, further efforts are needed to improve the implementation of geriatric recommendations.

(c) 2014 Elsevier Ltd. All rights reserved.

\section{Introduction}

Patients aged 65 or older have a significantly higher risk for cancer incidence and cancer mortality. ${ }^{1,2}$ Since the number of older patients with cancer will be increasing over time due to the aging of the world's population, clinicians observed and documented important treatment and outcome variations within this patient group (e.g. choice of therapy, treatment complications, evolution of functionality and quality of life, (overall) survival, etc.). ${ }^{2-6}$ This can be related to important heterogeneity of the older population and lack of appropriate care standards caused by insufficient accrual of older persons in clinical trials. As a consequence, published data report on non-evidence based adjustments of treatment guidelines and increased likelihood of under-treatment with a possible negative effect on survival. ${ }^{6-8}$

Implementation of the CGA (comprehensive geriatric assessment), which has been shown beneficial for several outcomes in acute geriatric care wards, ${ }^{9,10}$ is considered to be the most appropriate way to adapt to the multiple needs and restrictions of older patients. ${ }^{11}$ This method comprises four consecutive steps: (i) identifying patients who can benefit from a CGA; (ii) assessing these patients; (iii) developing recommendations for geriatric interventions based on the detected problems by the CGA; and (iv) implementing these recommendations. But since its implementation in oncology has mainly focused on screening and assessment, the term 'GA' (geriatric assessment) is preferred above CGA for this approach in older patients with cancer. ${ }^{11} \mathrm{GA}$ is "a multidimensional, interdisciplinary patient evaluation that leads to the identification of the general health status including medical, functional, cognitive, social, nutritional and psychological parameters". ${ }^{12}$

A nationwide Belgian pilot project (2009-2011) for uniform, multicenter implementation of GA in older patients with cancer was supported by the Cancer Plan (2008), in which improving geriatric oncology care was one of the 30 aims. The uniform implemented GA comprised detecting eligible patients, applying a screening tool (e.g. G $8^{13,14}$ ), and conducting a full GA if necessary. Participating hospitals were responsible for tailoring this GA into daily practice. As a consequence, in each hospital, one (or several) medical or paramedical graduate(s) was appointed to coordinate the performance of a GA. The generic term for such a person is further called a 'trained healthcare worker' (THCW). In the three-year period 3517 patients were included in this study. The first publication revealed that geriatric screening and assessment in older patients with cancer have a significant impact on the detection of unknown geriatric problems, leading to geriatric interventions ${ }^{15}$ and adapted treatment. ${ }^{16}$ During this initiative the need for surveying treating physicians' opinions concerning GA emerged. Therefore, we decided to conduct a survey at the end of the implementation period. The aim of this study was to identify treating physicians' general experiences and expectations regarding GA in older patients with cancer.

\section{Materials and Methods}

\subsection{Study Design}

A cross-sectional survey design was used. Data were collected in the months of June, July, and August 2012.

\subsection{Participants}

The survey was carried out in nine Belgian hospitals, including six academic and three non-academic institutions, spread all over the country's regions. All these hospitals participated in a multicenter GA implementation study, ${ }^{15}$ that initially included only 6 tumor types (1967 patients) and later all kinds of tumors (1550 patients). In every participating hospital a principal investigator was appointed to contact all treating physicians of older patients with cancer (age $\geq 70$ years old), whether they were inpatients or ambulatory treated.

\subsection{Questionnaire}

A questionnaire from a previous Belgian geriatric care survey ${ }^{17}$ was used to develop a new one, comprising two parts and appropriate for the current context. Face and content validity was assessed by all principal investigators.

The first part included general information about the hospital (e.g. region; character (i.e. academic or non-academic); number of beds and geriatric beds; number of geriatricians, medical oncologists, hematologists, radiotherapists, other oncological specialists; amount of admissions, admissions of patients aged 70 or older in the hospital and on geriatric and non-geriatric wards, newly detected cancer cases per year, newly detected cancer cases per year in patients aged 70 or older; and number of multidisciplinary oncological consults (MOCs)).

The second part included 25 questions in 6 main categories. The first category of questions $(n=4)$ comprised general respondent data (i.e. age, sex, medical specialism and years of working experience). The second category included 2 questions about the trained healthcare workers (THCWs) (1 question about the THCW's professional background; 1 question about detection of eligible patients). The third category comprised 2 questions about the GA population (1 question about the current amount of evaluated patients; 1 question about which patient group(s) should benefit from GA). The fourth category of 
questions included GA domains. Respondents used a 4-point Likert scale ranging from not important to very important to score self-estimated importance of separate GA domains (e.g. pain, social status, functionality, fall, fatigue, cognition, depression, nutrition, medication use). The fifth category included questions on GA results and geriatric recommendations (two questions about knowledge of GA results; four questions about implementation of geriatric recommendations). In the final category of questions, two five-point Likert scales were used for measuring respondents' opinion on importance (less important/important/very important/priority/ no opinion) and feasibility (absolutely not feasible/rather not feasible/rather feasible/completely feasible/no opinion) of GA related tasks for a THCW $(n=11)$ and a geriatrician $(n=8)$. The mode of both Likert scales per task was used to determine task classification (i.e. to what extent a task is rated important and feasible).

Finally, the Dutch questionnaire was translated in an identical French version.

\subsection{Data Collection}

After finalization of the questionnaire, paper and electronic versions were sent to all principal investigators, who had to complete the first part and offer the second to all physicians treating older patients with cancer in their hospital. Several electronic reminders were sent.

\subsection{Data Analysis}

Data were analyzed using SAS v9.2. Descriptive statistics (frequencies, percentages, modes means and standard deviations) were calculated as appropriate on the level of the total sample and the hospital level.

\subsection{Ethical Considerations}

The Ethical Committee of the University Hospitals Leuven reviewed and approved the multicenter GA implementation study in older patients with cancer, of which this study is a part. This survey was considered to have no ethical implications, as participation was voluntary and anonymous.

\section{Results}

\subsection{Sample Characteristics}

Eighty-two questionnaires from nine hospitals were returned, resulting in an overall response of $36.4 \%$. Response rate per hospital varied between $5.2 \%$ and $63.7 \%$. Response rate for Flanders, Wallonia and Brussels capital region was 38.4\%, 58.3\%, and $32.5 \%$, respectively. The main characteristics of participating hospitals and respondents are described in Table 1.

\subsection{Trained Healthcare Workers (THCW)}

All participating hospitals appointed at least one nurse as a THCW. In 5 hospitals, the team of THCWs comprised other disciplines as well (i.e. a social assistant $(n=1)$, an occupational therapist $(n=2)$, a psychologist $(n=1)$, a physician $(n=1)$, or a data manager $(n=1)$ ). Detection of patients, who could possibly benefit from geriatric screening and GA, was mostly done by both the treating physician and the THCW. Sometimes this specific part of the GA was supported by other staff members (e.g. ward nurses).

\subsection{GA Population}

Twenty-seven treating physicians (34.2\%) reported that at the moment of the survey GA was applied in $0 \%$ to $20 \%$ of their older patients. Fifteen respondents (19.0\%) stated this between $81 \%$ and $100 \%$.

Forty physicians (50.6\%) reported that GA should be applied in all older patients in whom a treatment decision needs to be made (i.e. in all new cancer cases and all older patients with progressive disease or relapse) (Table 2). Twenty-three $(29.1 \%)$ respondents would perform GA in all new cancer cases and in preselected older patients with progressive disease or relapse. Detailed results concerning the GA population are described in Table 2.

\subsection{GA Results and Geriatric Recommendations}

Sixty-six (82.6\%) respondents stated that GA results and geriatric recommendations had always or often reached the physician (Table 2). A third of respondents reported that it took three or more days for results being available. All treating physicians agree that GA results and geriatric recommendations should always or often be communicated to primary care. Sixteen (20.0\%) respondents stated this as a task for the THCW, while 35 (43.8\%) persons concluded that this is the treating physician's responsibility. Twenty-seven (33.8\%) respondents preferred shared responsibility. Half of respondents (52.6\%) experienced barriers while implementing geriatric recommendations with work-load as the leading cause (34.6\%). Detailed results concerning GA results and geriatric recommendations are described in Table 2.

\subsection{GA Domains}

Table 3 describes how important separate GA domains are estimated by treating physicians. Most respondents rated functionality (79.0\%), cognition (76.5\%), falls (60.5\%), nutrition (54.3\%), social status (49.4\%), depression (46.9\%), and medication use (43.2\%) as very important GA domains. More than half of treating physicians (54.3\%) reported fatigue as an important domain in GA. Thirty-three respondents $(40.7 \%)$ reported pain as less important. Five physicians (6.2\%) rated pain as not important within GA.

\subsection{Expectations Towards Trained Healthcare Workers and Geriatricians}

For THCWs, conducting a GA was rated as priority (45.6\%) and completely feasible (67.1\%). Detecting patients who can benefit from GA, communicating GA results, and follow-up of geriatric recommendation implementation were reported as very important (38.5\%, 40.5\%, and $42.3 \%$, respectively) and rather or completely feasible (45.9\%, $47.4 \%$, and $45.9 \%$, respectively) 
tasks. Attending all MOCs was stated less important (44.3\%) for THCWs.

For geriatricians, only one task (i.e. coordinating geriatric recommendations) was reported as very important (41.3\%) and rather feasible (38.0\%). Attending all (mostly weekly) MOCs, seeing all patients personally and organizing multidisciplinary consultation for a preselected group of patients, were appraised less important $(72.5 \%, 64.6 \%$, and $56.4 \%$, respectively) and absolutely not feasible $(62.5 \%$, $58.9 \%$, and $49.3 \%$, respectively) for a geriatrician. Detailed information about task classification can be consulted in Table 4.

\section{Discussion}

Previous research showed that a GA in the growing older cancer population is feasible and useful (e.g. additional problem detection, predictive and prognostic value). ${ }^{11,18}$ This is the first study identifying treating physicians' general experiences and expectations regarding GA in older patients with cancer after a multicenter implementation period.

A strange paradox is that published data often use (different) age cut-offs to decide whether patients with cancer are eligible for GA, while GA was introduced since chronological age is a poor descriptor of the heterogeneity in the ageing process. $^{3,15,19}$ If no GA inclusion criteria are predefined, Lazarovici et al. ${ }^{20}$ found that weight loss is the main reason for oncologists to refer older patients with cancer for a GA. Concerning eligibility criteria, more than half of the respondents stated that GA should ideally be applied in all patients, aged 70 years or older, in whom a treatment decision (i.e. in all new cancer cases and all patients with progressive disease or relapse) needs to be made. This supports the idea that an objective and comprehensive evaluation and follow-up of the global health are essential for optimizing treatment plans and

Table 1 - Characteristics of participating hospitals and respondents.

Characteristics of participating hospitals $(n=9)$

$n(\%)$

$\mathrm{M} \pm \mathrm{SD}(\min -\max )$

\begin{tabular}{ll}
\hline Region $(n=9)$ & \\
Flanders & $4(44.4)$ \\
Wallonia & $1(11.1)$ \\
Brussels, capitol region & $4(44.4)$ \\
Character $(n=9)$ & \\
Academic & $6(66.6)$ \\
Non-academic & $3(33.3)$
\end{tabular}

$(11.1)$

$(44.4)$

$(66.6)$

Number of beds $(n=9)$

Number of beds on a geriatric ward $(n=9)$

Number of geriatricians $(n=9)$

Number of medical oncologists $(n=9)$

Number of hematologists $(n=9)$

Number of radiotherapists $(n=9)$

Number of other oncologists $(n=8)$

Number of all patients admitted to the hospital in

one year ${ }^{\mathrm{a}}(n=8)$

Number of patients admitted to the hospital aged

70 years or older in one year ${ }^{\mathrm{a}}(n=7)$

On general geriatric wards $(n=8)$

On non-geriatric $\operatorname{wards}^{a}(n=7)$

Number of all newly detected cancer cases in the hospital

in one year ${ }^{\mathrm{a}}(n=8)$

Number of newly detected cancer cases in patients aged

70 or older in the hospital in one year ${ }^{\mathrm{a}}(n=7)$

Number of all MOCs in the hospital ${ }^{a}(n=8)$

$883.9 \pm 488.6(154-1798)$

$47.1 \pm 32.7(6-124)$

$2.9 \pm 1.9(1-6)$

$6.7 \pm 5.1(1-17)$

$5.3 \pm 3.1(1-10)$

$5.8 \pm 3.9(0-11)$

$20.9 \pm 26.6(2-84)$

$32,926.6 \pm 20,947.9(5247-64,497)$

$8735.1 \pm 5048.7(1273-16,763)$

$1314.3 \pm 1238.2(375-3767)$

$7571.3 \pm 4297.2(1273-14,584)$

$1941.3 \pm 1383.7(600-5123)$

$638.6 \pm 348.5(421-1399)$

$3306.7 \pm 1998.7(800-6722)$

$\mathrm{M} \pm \mathrm{SD}(\min -\max )$

Characteristics of respondents $(n=82)$

$n(\%)$

$44.6 \pm 8.7(28-66)$

Age $(n=81)$

Sex $(n=82)$

Male

Female

$44(53.7)$

$38(46.3)$

Medical specialism $(n=81)$

Medical oncologists

$26(32.1)$

Hematologists

$14(17.3)$

$10(12.3)$

$23(28.4)$

$8(9.8)$

Other oncologists

Other

Years of work experience in current specialism $(n=82)$

$14.7 \pm 9.2(1-35)$

Legend: $\mathrm{M}=$ mean; $\mathrm{SD}$ = standard deviation; $\min =$ minimum; $\max =$ maximum; $\mathrm{MOC}=$ multidisciplinary oncological consults.

a Numbers of the year $2010(n=2), 2011(n=5)$, or year not specified $(n=2)$. 
outcomes. ${ }^{21}$ However, international literature has not yet focused on the ideal moment for conducting a GA, and also the timing and frequency of repeated follow-up have not been strongly defined.

Implementation of GA in clinical practice has mainly been impeded by high workload, since GA is time-consuming and poorly financially rewarded by most health insurance systems. For feasibility and efficacy reasons, the use of validated screening tools-as in the current implementation projectcan be useful for identifying the $20-30 \%$ of patients, aged 70 years or older, in whom full GA cannot find any important impairment and who have a good outcome in terms of survival and functional performance. ${ }^{22}$ These patients probably do not benefit from GA.

There was great variation in composition of GA teams, with the nurse as core member in all teams. Five other healthcare disciplines conducted a GA as well. It might be possible that in the current context a trained nurse is considered the most appropriate person for collecting GA data (i.e. detection of eligible patients and screening and assessment of these persons) from an organizational, practical and economical point of view. A former study that surveyed the implementation of inpatient geriatric consultation teams and geriatric resource nurses in Belgian hospitals, reported that in nearly all teams a nurse and

Table 2 - Treating physicians' experiences and expectations regarding GA in older patients with cancer $(n=82)$.

Questions on GA population

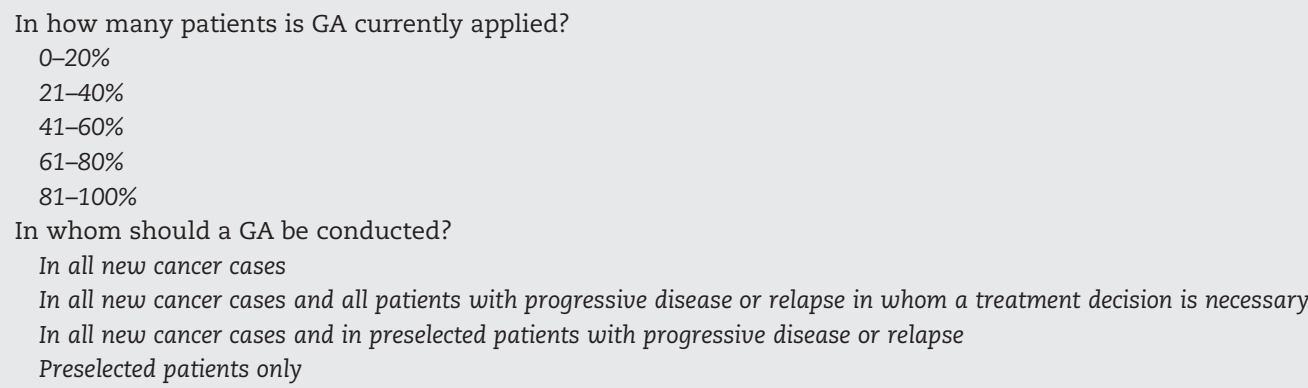

Questions on GA results and geriatric recommendations

\begin{tabular}{|c|c|}
\hline \multicolumn{2}{|l|}{ How frequent did GA results reach the treating physician in time? } \\
\hline Never & $1(1.3)$ \\
\hline Seldom & $13(16.3)$ \\
\hline Often & $33(41.3)$ \\
\hline Always & $33(41.3)$ \\
\hline \multicolumn{2}{|c|}{ How many days does it take for GA results to be available for the treating physician? } \\
\hline The same day & $5(6.3)$ \\
\hline 1 day & $7(8.8)$ \\
\hline 2 days & $17(21.3)$ \\
\hline 3 days & $11(13.8)$ \\
\hline 4 days or more & $14(17.5)$ \\
\hline Not relevant & $7(8.8)$ \\
\hline I don't know & $19(23.8)$ \\
\hline \multicolumn{2}{|l|}{ How frequent should GA results be communicated to primary care? } \\
\hline Never & 0 \\
\hline Seldom & 0 \\
\hline Often & $63(78.8)$ \\
\hline Always & $17(21.3)$ \\
\hline \multicolumn{2}{|l|}{ Who should communicate GA results to primary care? } \\
\hline Treating physician & $16(20.0)$ \\
\hline Trained healthcare worker & $35(43.8)$ \\
\hline Treating physician and trained healthcare worker & $27(33.8)$ \\
\hline Other & $5(6.3)$ \\
\hline \multicolumn{2}{|c|}{ Do you experience barriers while implementing geriatric recommendations based on the GA results? } \\
\hline No & $37(47.4)$ \\
\hline Yes & $41(52.6)$ \\
\hline \multicolumn{2}{|c|}{ Which barrier(s) do you experience while implementing geriatric recommendations based on the GA results? } \\
\hline Work load & $27(34.6)$ \\
\hline Insufficient possibilities for making referrals & $13(16.7)$ \\
\hline Unclear geriatric paths & $17(21.8)$ \\
\hline Lack of communication between professional healthcare workers & $17(21.8)$ \\
\hline Other & $5(6.4)$ \\
\hline
\end{tabular}

Legend: GA = geriatric assessment 
Table 3 - Importance of separate GA domains estimated by treating physicians.

\begin{tabular}{|c|c|c|c|c|}
\hline \multirow[b]{2}{*}{ GA domain } & \multicolumn{4}{|c|}{ Importance $n(\%)$} \\
\hline & Very important & Important & Less important & Not important \\
\hline Functionality & 64 (79.0) & $17(21.0)$ & - & - \\
\hline Cognition & $62(76.5)$ & $19(23.5)$ & - & - \\
\hline Falls & $49(60.5)$ & $27(33.3)$ & $5(6.2)$ & - \\
\hline Nutrition & $44(54.3)$ & 32 (39.5) & $4(4.9)$ & $1(1.2)$ \\
\hline Social status & 40 (49.4) & 34 (42.0) & $6(7.4)$ & $1(1.2)$ \\
\hline Depression & 38 (46.9) & $36(44.4)$ & $7(8.6)$ & - \\
\hline Medication & 35 (43.2) & $33(40.7)$ & $12(14.8)$ & $1(1.2)$ \\
\hline Fatigue & $13(16.0)$ & $44(54.3)$ & $22(27.2)$ & $2(2.5)$ \\
\hline Pain & $14(17.3)$ & $29(35.8)$ & $33(40.7)$ & $5(6.2)$ \\
\hline
\end{tabular}

an occupational therapist were core members. ${ }^{17}$ International literature reports that GA data collection can be done by very different persons after appropriate training (e.g. trained researcher, trained nurse practitioner, clinical nurse specialist, geriatrician, treating physician). ${ }^{4,5,15,23}$ In general, it is not an issue who collects data, as long as these are reliable and valid.

More important is that patients do not benefit from geriatric assessment only. Adherence to tailored care planning following GA is crucial for GA effectiveness. First, this implies that treating physicians need to be aware of GA results and their implications when treatment decisions are being made. Fourteen treating physicians (17.6\%) reported that GA information had never or seldom reached them in time. This needs to be improved. In addition, the time period between a GA and availability of GA results for the treating physician can improve as well, since $31.3 \%$ of respondents estimated that GA results were available after only 3 days or longer. Integrating GA in electronic patient charts can

Table 4 - Treating physicians' opinion on importance and feasibility of GA-related tasks for a THCW and a geriatrician*.

\begin{tabular}{|c|c|c|c|c|c|c|c|c|c|c|}
\hline \multirow[b]{2}{*}{ Possible tasks of THCW } & \multicolumn{5}{|c|}{ Importance (\%) } & \multicolumn{5}{|c|}{ Feasibility (\%) } \\
\hline & NO & $\mathrm{P}$ & VI & I & LI & NO & $\mathrm{CF}$ & $\mathrm{RF}$ & RNF & ANF \\
\hline Conducting a GA & 1.3 & 45.6 & 38.0 & 15.2 & 0.0 & 1.3 & 67.1 & 26.3 & 5.3 & 0.0 \\
\hline Detecting patients who can benefit from GA & 1.3 & 20.5 & 38.5 & 33.3 & 6.4 & 1.4 & 32.4 & 45.9 & 16.2 & 4.1 \\
\hline $\begin{array}{l}\text { Communicating GA results and geriatric recommendations to treating } \\
\text { physician/other healthcare workers }\end{array}$ & 0.0 & 38.0 & 40.5 & 20.3 & 1.3 & 0.0 & 47.4 & 40.8 & 11.8 & 0.0 \\
\hline Follow-up of geriatric recommendation implementations by the treating physician & 1.3 & 5.1 & 42.3 & 41.0 & 10.3 & 2.7 & 10.8 & 45.9 & 33.8 & 6.8 \\
\hline Discussing all evaluated patients with a geriatrician & 1.3 & 7.6 & 21.5 & 36.7 & 32.9 & 6.6 & 7.9 & 25.0 & 38.2 & 22.4 \\
\hline Discussing a preselected group of evaluated patients with a geriatrician & 2.6 & 28.2 & 25.6 & 29.5 & 14.1 & 4.0 & 42.7 & 42.7 & 8.0 & 2.7 \\
\hline Performing patient follow-up on fixed moments & 1.3 & 7.7 & 34.6 & 39.7 & 16.7 & 2.6 & 7.9 & 42.1 & 42.1 & 5.3 \\
\hline Teaching in-service training & 5.1 & 16.7 & 15.4 & 48.7 & 14.1 & 10.8 & 17.6 & 55.4 & 9.5 & 6.8 \\
\hline $\begin{array}{l}\text { Attending team meetings/patient discussion on a specific ward } \\
\text { (e.g. inpatient oncology ward) }\end{array}$ & 1.3 & 13.0 & 20.8 & 45.5 & 19.5 & 6.8 & 14.9 & 36.5 & 37.8 & 4.1 \\
\hline Attending all MOCs & 3.8 & 8.9 & 15.2 & 27.8 & 44.3 & 6.6 & 13.2 & 13.2 & 43.4 & 23.7 \\
\hline \multirow[t]{3}{*}{ Attending a preselected group of MOCs } & 5.2 & 14.3 & 28.6 & 35.1 & 16.9 & 7.9 & 23.7 & 40.8 & 25.0 & 2.6 \\
\hline & \multicolumn{5}{|c|}{ Importance (\%) } & \multicolumn{5}{|c|}{ Feasibility (\%) } \\
\hline & NO & $P$ & VI & I & $\mathrm{LI}$ & NO & $\mathrm{CF}$ & $\mathrm{RF}$ & RNF & ANF \\
\hline Coordinating geriatric recommendations & 2.5 & 17.5 & 41.3 & 36.3 & 2.5 & 8.5 & 31.0 & 38.0 & 18.3 & 4.2 \\
\hline Supervising the evaluation of patients through GA & 3.8 & 15.0 & 31.3 & 42.5 & 7.5 & 7.0 & 22.5 & 38.0 & 19.7 & 12.7 \\
\hline Attending all MOCs & 3.8 & 2.5 & 2.5 & 18.8 & 72.5 & 5.6 & 1.4 & 1.4 & 29.2 & 62.5 \\
\hline Attending a preselected group of MOCs & 7.8 & 5.2 & 14.3 & 44.2 & 28.6 & 7.0 & 4.2 & 36.6 & 31.0 & 21.1 \\
\hline Seeing all patients personally on consultation, day clinic, inpatient wards... & 5.1 & 1.3 & 8.9 & 20.3 & 64.6 & 5.5 & 2.7 & 5.5 & 27.4 & 58.9 \\
\hline $\begin{array}{l}\text { Seeing a preselected group of patients personally on consultation, } \\
\text { day clinic, inpatient wards... }\end{array}$ & 3.8 & 10.1 & 34.2 & 48.1 & 3.8 & 6.9 & 13.9 & 65.3 & 8.3 & 5.6 \\
\hline $\begin{array}{l}\text { Organizing multidisciplinary consultation along with oncologist/organ } \\
\text { specialist... for all evaluated patients }\end{array}$ & 1.3 & 5.1 & 9.0 & 28.2 & 56.4 & 5.5 & 4.1 & 8.2 & 32.9 & 49.3 \\
\hline $\begin{array}{l}\text { Organizing multidisciplinary consultation along with oncologist/organ } \\
\text { specialist... for a preselected group of evaluated patients }\end{array}$ & 1.3 & 11.5 & 25.6 & 44.9 & 16.7 & 4.2 & 11.3 & 49.3 & 25.4 & 9.9 \\
\hline
\end{tabular}

Legend: THCW = trained healthcare worker; $\mathrm{LI}=$ less important; $\mathrm{I}$ = important; $\mathrm{VI}$ = very important; $\mathrm{P}$ = priority; $\mathrm{NO}=$ no opinion; $\mathrm{ANF}=$ absolutely not feasible; $\mathrm{RNF}$ = rather not feasible; $\mathrm{RF}$ = rather feasible; $\mathrm{CF}=$ completely feasible; $\mathrm{NO}$ = no opinion; $\mathrm{GA}$ = geriatric assessment; $\mathrm{MOC}=$ multidisciplinary oncological consults.

The bold value indicates the mode. 
improve these communication problems. Second, geriatric recommendations need to be feasible, which was a concern of respondents, with work-load as the leading cause. Insufficient possibilities for making referrals, lack of communication between professional healthcare workers, and unclear geriatric paths were other factors contributing to feasibility problems. These challenge the relevance of assessing patients for domains, in which no intervention is possible due to local circumstances (e.g. no memory clinic available). This backward reasoning may be an argument for deleting domains from a GA, since the added value of GA lies in improving/correcting detected deficiencies. However, in oncology, testing for a domain in which no (highly effective) intervention is possible can be justified by the hypothesis that in case of one or more specific deficiencies downgrading or omission of therapy might be beneficial for the patient. Further research is necessary to explore this. The recent International Society of Geriatric Oncology (SIOG) consensus paper on GA documented the great heterogeneity in GA composition and reported that all GA domains are relevant. ${ }^{11}$ These results align with the reported importance of separate GA domains. Nearly all domains were rated (very) important, except for pain, which was not considered as a GA domain by the SIOG taskforce. A possible explanation may be that pain evaluation as a standard GA component is little innovative, since most hospitals have already been giving a lot of attention to this item, both in young and old. ${ }^{24}$

Although the ideal GA format for use in geriatric oncology cannot be determined due to variation in local preferences and resources present, this study identified core GA-related tasks for both THCWs and geriatricians in the Belgian healthcare system. While treating physicians see geriatricians mainly responsible for coordination of geriatric recommendations, they also stated that THCWs should especially focus on geriatric screening and assessment, communication of GA results to the treating physician, and follow-up of geriatric recommendations.

This study has some limitations and its context and design need to be kept in mind while interpreting the results. The overall response rate was rather low (36.4\%), but can be explained by the timing of the survey. The questionnaire was sent to all physicians treating older patients with cancer in each site, but many of the treating physicians did not yet have experience with the GA since in the initial phase, only 6 tumor types had been included. ${ }^{15}$ The response rate within the group of treating physicians who had experience with GA is probably higher, but cannot be defined exactly. Nevertheless, we were able to investigate the experience of 82 treating physicians which is a large number allowing a view on the experience with GA in routine clinical practice.

Next, only treating physicians' opinion and experiences with GA were surveyed. Further research should definitely explore the view of THCWs and geriatricians. Another limitation is that psychometric properties of the questionnaire have not been tested, which could have affected the results. Still, this study is interesting and relevant as it revealed considerations for the implementation of GA in older patients with cancer (see Table 5). Its originality lies in the broad implementation of GA and the involvement of all physicians treating older patients with cancer including all kind of tumour types.

\section{Conclusion}

This survey shows the importance of GA implementation in daily clinical practice. THCWs can play an important role in the coordination of the GA process, and geriatricians can be

\section{Table 5 - Considerations for GA implementation resulting from this Belgian survey.}

Functionality, cognition, falls, nutrition, social status, depression, medication use, and fatigue are considered important GA

domains by oncologists and other physicians treating older cancer patients.

Treating physicians believe that GA should ideally be applied in all patients in whom a treatment decision (i.e. in all new cancer cases and all patients with progressive disease or relapse) needs to be made.

GA results (including recommendations for geriatric interventions) do not always reach treating physicians in time, and structural efforts are required to improve this.

A system using a THCW to coordinate the performance of GA is appreciated by physicians treating older cancer patients since this allows to evaluate many older cancer patients in an efficient manner. The THCW was generally a nurse, but also other healthcare workers were appointed for this position in several hospitals.

THCWs' priority is conducting GA, but also detecting patients who can benefit from GA, communicating GA results and follow-up of geriatric recommendation implementation swere considered as important tasks by treating physicians.

Presence of a geriatrician is proposed by treating physicians to coordinate the recommendations resulting from GA.

Implementation of GA recommendations-the most crucial step in achieving patient benefit from GA and an area for significant improvement-is mainly been impeded by high work load. 
integrated to set up recommendations for the implementation of geriatric interventions, but preferably in a structured way so they can focus on the patients with more difficult/ multidimensional problems.

\section{Disclosures and Conflict of Interest Statements}

None declared.

\section{Author Contributions}

Study concepts: C Kenis, J Flamaing, K Milisen, H Wildiers Study design: All authors

Data acquisition: C Kenis, P Heeren

Quality control of data and algorithms: C Kenis, P Heeren

Data analysis and interpretation: All authors

Statistical analysis: JP Lobelle

Manuscript preparation: C Kenis, P Heeren, J Flamaing, K Milisen, $\mathrm{H}$ Wildiers

Manuscript editing: All authors

Manuscript review: All authors

\section{Funding Source}

This work was supported by the Cancer Plan, a grant provided by the Federal Public Service of Health, Food Chain Safety and Environment, Belgium (Cancer Plan 2009-2011; grant number: NKP_24_005).

HW is a recipient of a grant of the 'Fonds Voor Wetenschappelijk Onderzoek Vlaanderen' (1802211N).

\section{REFERENCES}

1. Howlader N, Noone AM, Krapcho M, Garshell J, Neyman N, Altekruse SF, Kosary CL, Yu M, Ruhl J, Tatalovich Z, Cho H, Mariotto A, Lewis DR, Chen HS, Feuer EJ, Cronin KA, editors. SEER cancer statistics review, 1975-2010. Bethesda, MD: National Cancer Institute; 2013. [based on November 2012 SEER data submission, posted to the SEER website, April 3]. Available from: http://seer.cancer.gov/csr/1975_2010/].

2. Smith BD, Smith GL, Hurria A, Hortobagyi GN, Buchholz TA. Future of cancer incidence in the United States: burdens upon an aging, changing nation. J Clin Oncol 2009;27(17):2758-2765.

3. Hurria A, Togawa K, Mohile SG, Owusu C, Klepin HD, Gross CP, et al. Predicting chemotherapy toxicity in older adults with cancer: a prospective multicenter study. J Clin Oncol 2011;29(25):3457-3465.

4. Aaldriks AA, Giltay EJ, le Cessie S, van der Geest LG, Portielje JE, Tanis BC, et al. Prognostic value of geriatric assessment in older patients with advanced breast cancer receiving chemotherapy. Breast 2013;22(5):753-760.

5. Hamaker ME, Buurman BM, van Munster BC, Kuper IM, Smorenburg CH, de Rooij SE. The value of a comprehensive geriatric assessment for patient care in acutely hospitalized older patients with cancer. Oncologist 2011;16(10):1403-1412.

6. Puts MT, Hardt J, Monette J, Girre V, Springall E, Alibhai SM. Use of geriatric assessment for older adults in the oncology setting: a systematic review. J Natl Cancer Inst 2012;104(15):1133-1163.
7. Bouchardy C, Rapiti E, Fioretta G, Laissue P, Neyroud-Caspar I, Schafer $\mathrm{P}$, et al. Undertreatment strongly decreases prognosis of breast cancer in elderly women. J Clin Oncol 2003;21(19): 3580-3587.

8. Giordano SH, Hortobagyi GN, Kau SW, Theriault RL, Bondy ML. Breast cancer treatment guidelines in older women. J Clin Oncol 2005;23(4):783-791.

9. Van Craen K, Braes T, Wellens N, Denhaerynck K, Flamaing J, Moons $\mathrm{P}$, et al. The effectiveness of inpatient geriatric evaluation and management units: a systematic review and meta-analysis. J Am Geriatr Soc 2010;58(1):83-92.

10. Ellis G, Whitehead MA, O'Neill D, Langhorne P, Robinson D. Comprehensive geriatric assessment for older adults admitted to hospital. Cochrane Database Syst Rev 2011;7: CD006211.

11. Wildiers H, Heeren P, Puts M, Topinkova E, Janssen-Heijnen MLG, Extermann M, Falandry C, et al. SIOG consensus on geriatric assessment in older cancer patients; 2013 [Submitted to J Clin Oncol].

12. Aapro M, Extermann M, Repetto L. Evaluation of the elderly with cancer. Ann Oncol 2000;11(Suppl 3):223-229.

13. Bellera CA, Rainfray M, Mathoulin-Pelissier S, Mertens C, Delva F, Fonck M, et al. Screening older cancer patients: first evaluation of the G-8 geriatric screening tool. Ann Oncol 2012;23(8):2166-2172.

14. Kenis C, Decoster L, Van Puyvelde K, De Greve J, Conings G, Milisen $\mathrm{K}$, et al. Performance of two geriatric screening tools in older patients with cancer. J Clin Oncol 2013;32(1):19-26.

15. Kenis C, Bron D, Libert Y, Decoster L, Van Puyvelde K, Scalliet $\mathrm{P}$, et al. Relevance of a systematic geriatric screening and assessment in older patients with cancer: results of a prospective multicentric study. Ann Oncol 2013;24(5): 1306-1312.

16. Decoster L, Kenis C, Van Puyvelde K, Flamaing J, Conings G, De Greve J, et al. The influence of clinical assessment (including age) and geriatric assessment on treatment decisions in older patients with cancer. J Geriatr Oncol 2013;4(3):235-241.

17. Deschodt M, Flamaing J, Rock G, Boland B, Boonen S, Milisen K. Implementation of inpatient geriatric consultation teams and geriatric resource nurses in acute hospitals: a national survey study. Int J Nurs Stud 2012;49(7):842-849.

18. Wildiers H, Kenis C. Comprehensive geriatric assessment (CGA) in older oncological patients: why and how? J Geriatr Oncol 2012;3:174-176.

19. Girones R, Torregrosa D, Maestu I, Gomez-Codina J, Tenias JM, Costa RR. Comprehensive geriatric assessment (CGA) of elderly lung cancer patients: a single-center experience. J Geriatr Oncol 2012;3(2):98-103.

20. Lazarovici C, Khodabakhshi R, Leignel D, Fabre-Guillevin E, Minard A, Gisselbrecht M. Factors leading oncologists to refer elderly cancer patients for geriatric assessment. J Geriatr Oncol 2011;2(3):194-199.

21. Kanesvaran R, Li H, Koo KN, Poon D. Analysis of prognostic factors of comprehensive geriatric assessment and development of a clinical scoring system in elderly Asian patients with cancer. J Clin Oncol 2011;29(27):3620-3627.

22. Kenis C, Decoster L, Van Puyvelde K, De Greve J, Conings G, Milisen $\mathrm{K}$, et al. Performance of two geriatric screening tools in older patients with cancer. J Clin Oncol 2014;32(1):19-26.

23. Ketelaars L, Pottel L, Lycke M, Goethals L, Ghekiere V, Santy L, et al. Use of the Freund clock drawing test within the mini-cog as a screening tool for cognitive impairment in elderly patients with or without cancer. J Geriatr Oncol 2013;4(2): 174-182.

24. International JC. Joint Commission International Accreditation Standards for Hospitals. 4th edition. Oakbrook Terrace, IL: Joint Commission Resources; 2012. 